\title{
Quiet Evening; Cat; Then Rain
}

Seen from behind the fine mesh of a screen intended to prevent particles of outside from drifting in, the back yard, newly mown this evening, looks more than ever like a tapestryor a tesselation by some meticulous god of lawns, vines, and tidy gardens.

The whole town might look like this if we could see it through a giant scrimlaid out in tiny squares, like a town caught in a web: where each interstice might signify a death, a place a soul tore through. Our city's like most in the midwest, built on a grid of twelve blocks per mile, and it consisted, for just about its first ten decades, of twelve by twelve-144, minus the five reserved for the dead in the northeast corner. Say a neighbor goes: an auctioneer soon comes, and people gather and disperse, taking (as I have taken) muslin or mason jars, the flotsam and jetsam of the oceanic sadness auctions are: a billow washes us, recedes. In the vacant house, the blinds will have been pulled: that keeps the heat in, or the outside out of the house, more than likely a boxy affair of white clapboard -as mine is, all its windows open, this July evening, to drifting stars, and fireflies, and the odor of Quaker Oats from the plant across the river. 
What wild men

got swept here in a storm, working

in slaughter houses, driving

the country roads at night, flinging

gravel as they passed? That dust rises, falls

in living rooms, a grit we wipe away

each week with a damp cloth: we keep

the outside out. They're mostly

gone now, the packing houses

closed; this is a quiet town,

our school named for a famous nineteenth-century poet. . . .

And still we watch, we watch,

as night stirs in the garden,

and something moves, voluptuous and dark,

under the trees. The moon

has risen like an octopus,

and moths flutter whitely against the screen

beyond which stand

the lawnchairs' pallor, catalpas undulous

and gesturing. Meow. The cat wants in,

everything wants in, it seems, this evening,

only the screen's fine mesh opposing

owl calls, brr of mothwing, ashes

descending with the rain. ... Water

sweeps the lawn, excites the orchestra

of trees, of cornstalks, bluejeans

swaying on the line, pinned in place. . . It's time

to close the house. Our faces pressed

against plate glass, the outside's now

an underwater scene: waves convulse

the windows: what's outside

wants in again. It's late. 